Boise State University

ScholarWorks

Marketing and Finance Faculty Publications and

Presentations

Department of Marketing and Finance

8-1-2012

Implementing Changes in Marketing Strategy: The Role of Perceived Outcome- and Process-Oriented Supervisory Actions

Shikhar Sarin

Boise State University

Goutam Challagalla

Georgia Institute of Technology

Ajay K. Kohli

Georgia Institute of Technology 
This study investigates the role of supervisors in implementing changes in marketing strategy. The authors propose that perceptions of outcome-oriented supervisory actions influence salespeople's primary appraisals of a strategic change (i.e., whether the change will affect them) and that perceptions of process-oriented supervisory actions influence salespeople's secondary appraisals (i.e., whether they can cope with the impact of the change on them). The results from a study of 828 salespeople in 204 branches of a large distributor of industrial goods provide evidence that perceived outcome risk containment and outcome reward emphasis enhance primary appraisals, whereas perceived process risk containment and process reward emphasis enhance secondary appraisals. In turn, the authors find that salespeople's primary and secondary appraisals influence their change implementation behaviors, leading to successful change implementation. Notably, they also find that (outcome and process) risk containment has a greater influence on appraisals of salespeople with a higher performance orientation, but the effects of (outcome and process) reward emphases are invariant across salespeople's performance orientation. The findings suggest that successful implementation of strategic change may depend not merely or even primarily on giving rewards to salespeople for implementing change but also on limiting salespeople's risks and recognizing them for their change-related efforts.

Keywords: marketing strategy, change implementation, sales management, multichannel marketing, business-to-business marketing

\section{Implementing Changes in Marketing Strategy: The Role of Perceived Outcome- and Process-Oriented Supervisory Actions}

Firms periodically need to change their marketing strategies in response to competitive moves, internally generated opportunities, and technological developments. For example, a new competitor entering the market may prompt a

* Shikhar Sarin is Kirk and Marsha Smith Professor of Marketing, College of Business and Economics, Boise State University (e-mail: ssarin@ boisestate.edu). Goutam Challagalla is Associate Professor of Marketing (e-mail: goutam.challagalla@mgt.gatech.edu), and Ajay K. Kohli is Gary T. and Elizabeth R. Jones Chair (e-mail: ajay.kohli@mgt.gatech.edu), College of Management, Georgia Institute of Technology. The authors thank the participating organization for its strong support. In particular, they thank Michael DeCata and Richard J. Esce for their assistance with the study. They also thank Steve Brown, Robert Brennan, and Jason Newsom for their helpful comments. All authors contributed equally to the study. Jan Heide served as associate editor for this article. firm to target different customer segments and/or serve them differently. Similarly, new developments in technology (e.g., Internet) may suggest that a firm should serve its customers differently. It is relatively easy for firms to formulate ideas about how their marketing strategies should change but much more difficult to actually implement changes in strategy. This article focuses on the role of sales supervisors in influencing salespeople to implement changes in marketing strategies.

Researchers have long recognized the critical importance of marketing implementation (e.g., Bonoma 1984; Bonoma and Crittenden 1988). The topic has received some muchneeded attention, though the cumulative body of work remains limited (e.g., Chimhanzi and Morgan 2005). Existing research on the topic falls into three broad areas. One 
set of studies focuses on marketing implementation at the functional/organizational level and implementation by managers (e.g., Hutt and Speh 1984; Noble and Mokwa 1999; Walker and Ruekert 1987). A second set of studies focuses on factors that encourage employees to initiate a change or adapt to it (e.g., Ahearne et al. 2010; Morrison and Phelps 1999; Scott and Bruce 1994). A third set of studies examines the implementation of a change by frontline employees after an organization has decided on it - a major challenge sales and marketing managers face (Colletti and Chonko 1997; Hurley 1998). For example, Ye, Marinova, and Singh (2007) examine the effect of a cost containment versus revenue generation emphasis on frontline employees' strategic change implementation.

The present study adds to the third set of studies by focusing on the influence of sales supervisors on their salespeople's implementation of a strategic change. Our study focuses on a firm changing its go-to-market strategy from one that primarily depends on offline channels (salespeople) to one that primarily relies on online channels (Internet). "Strategic change implementation" in this context refers to salespeople getting their customers to transact business using the Internet rather than through the salespeople themselves.

A strategic change can be stressful for salespeople/ employees (Lafferty and Griffin 2006; Marshall and Cooper 1979). Stress theory, developed by Lazarus (1980) and Lazarus and Folkman (1984), suggests that upon encountering a stressor event, such as a strategic change, employees conduct two kinds of appraisals: primary and secondary. Primary appraisals involve employees evaluating the event's impact on their well-being, which could be favorable or unfavorable (Beehr and Franz 1986; Lazarus and Folkman 1984). For example, a strategic change may require employees to learn new skills, interact with new customers, and/or work longer hours. Secondary appraisals involve employees evaluating their ability to cope with the event's impact on them by considering their personal, social, economic, and organizational resources (Latack, Kinicki, and Prussia 1995). Thus, in the preceding example, salespeople would assess their ability to learn new skills, relate well to new customers, and allocate more hours to their work. Several researchers note that primary and secondary appraisals are independent and can occur virtually simultaneously (e.g., Chang 1998; Folkman and Lazarus 1985; Folkman et al. 1986; Lowe et al. 2003). These appraisals influence employees' psychological, physiological, and behavioral responses to stressor events (Kahn and Byosiere 1998; Lazarus and Folkman 1984).

Stress theory suggests that a salesperson faced with a change in go-to-market strategy of his or her firm conducts primary and secondary appraisals of the strategic change. If the appraisals are favorable, the salesperson is more likely to implement the change in strategy (see Lafferty and Griffin 2006; Mack, Nelson, and Quick 1998). In contrast, if the appraisals are unfavorable, the salesperson is likely to adopt a "wait and see" attitude, resist the change, or possibly even sabotage it (e.g., by portraying the change negatively to customers).

What actions can supervisors take to influence salespeople's primary and secondary appraisals and thus influence the extent to which they implement the change? The literature suggests that supervisors can focus their attention on salespeople's selling-related outcomes, selling processes, or both (e.g., Anderson and Oliver 1987; Jaworski 1988). Thus, supervisors can encourage salespeople to implement change in two broad ways. First, they can engage in outcomeoriented actions; that is, they can limit salespeople's risks associated with change implementation outcomes and emphasize rewards associated with them. Second, they can engage in process-oriented actions; in other words, they can limit salespeople's risks associated with change implementation processes and emphasize rewards associated with them (see Figure 1).

We hypothesize that perceptions of supervisory outcomeoriented actions influence salespeople's primary appraisals of a strategic change (i.e., whether the change has an impact on their well-being) and that perceptions of supervisory process-oriented actions influence salespeople's secondary appraisals (i.e., whether they can cope with the impact of the change on them). Furthermore, we hypothesize that the influence of these perceived supervisory actions is greater on salespeople with higher performance orientation (because they are likely to be more attentive to supervisors, as Ahearne et al. [2010], Harris, Mowen, and Brown [2005], and Sujan, Weitz, and Kumar [1994] suggest). In turn, we hypothesize that salespeople's primary and secondary appraisals influence their change implementation behaviors and outcomes (see Figure 2).

Findings from a study of 828 salespeople in 204 sales branches of a large distributor of industrial goods provide support for most of our hypotheses. At a more granular level, they suggest that successful implementation of strategic change depends not merely or even primarily on giving salespeople rewards for successfully implementing change but also on limiting salespeople's risks and recognizing them for their change-related efforts. These findings offer useful insights to managers for implementing changes in marketing strategy.

\section{THEORETICAL FRAMEWORK}

Our study context involves a company's salespeople being asked to get their customers to transact with the company on the Internet rather than through the salespeople. The stress and change management literatures suggest that the strategic change is likely to make salespeople focus on outcome-related risks and rewards - that is, whether successful implementation of the change will be good or bad for them personally (see Hunter and Thatcher 2007). For

Figure 1

SUPERVISORY ACTIONS INFLUENCING STRATEGIC CHANGE IMPLEMENTATION BY SALESPEOPLE

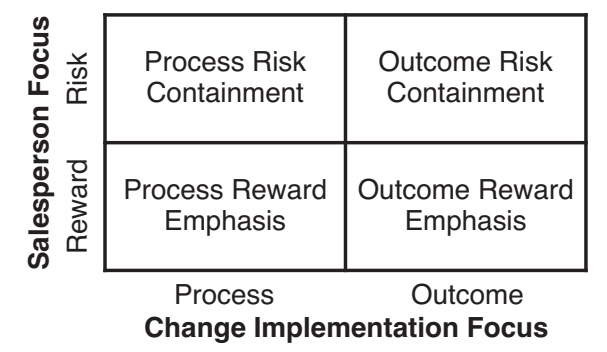


Figure 2

IMPLEMENTING STRATEGIC CHANGE: EFFECTS OF PERCEIVED OUTCOME- AND PROCESS-ORIENTED SUPERVISORY ACTIONS

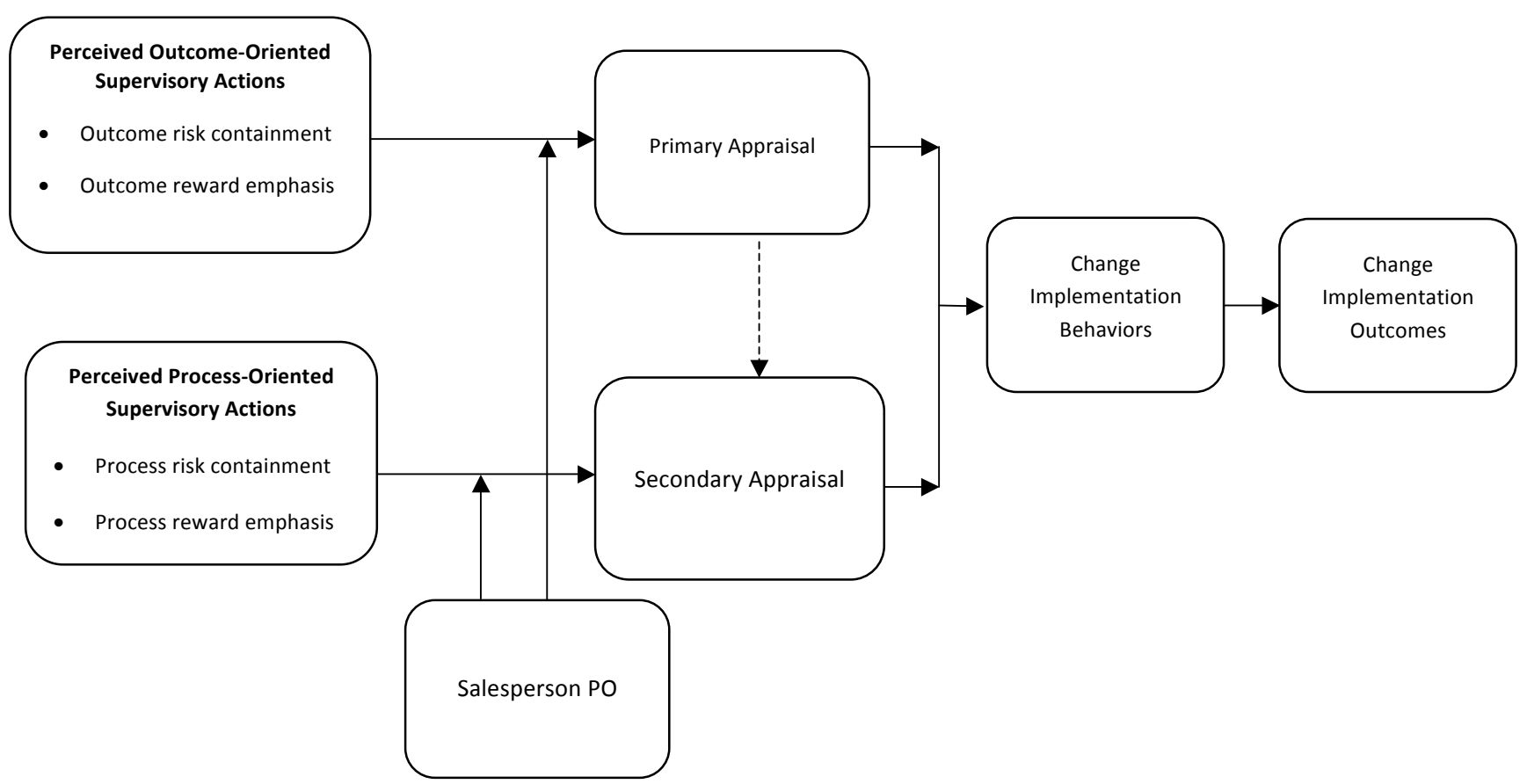

Notes: Control variables are not shown in the model. The dashed arrow represents an empirical exploration rather than a relationship based on prior theory.

example, salespeople are likely to assess risks to their compensation resulting from the change implementation. In addition, the strategic change is likely to make salespeople focus on process-related risks and rewards - that is, whether their behaviors (or absence of behaviors) directed at implementing the strategic change will be appreciated or criticized by supervisors (see Hunter and Thatcher 2007). For example, salespeople may worry about whether their supervisor will react positively or negatively to their sometimes embarrassing and flawed efforts to convert customers to the Internet. In summary, a strategic change is likely to make salespeople focus on change implementation outcomerelated risks and rewards as well as process-related risks and rewards.

How might sales supervisors address salespeople's strategic change-related concerns? Drawing on the works of Anderson and Oliver (1987) and Jaworski (1988), we propose that supervisors can address these concerns of salespeople by taking outcome-oriented actions, process-oriented actions, or both. Furthermore, these supervisory actions can each focus on limiting or containing risks of change implementation to salespeople or on emphasizing rewards of change implementation for salespeople (see Challagalla and Shervani 1996; Self, Armenakis, and Schraeder 2007). Thus, supervisory outcome-oriented actions can contain/ limit outcome-related risks or emphasize outcome-related rewards of change implementation for salespeople. Similarly, supervisory process-oriented actions can contain/limit process-related risks or emphasize process-related rewards of change implementation for salespeople (see Figure 1).

We investigate the effects of perceived supervisory outcome- and process-oriented actions on salespeople's pri- mary and secondary appraisals and, in turn, their effects on change implementation. We first draw on the literature on outcome and process controls and on risk and rewards (e.g., Anderson and Oliver 1987; Challagalla and Shervani 1996; Cravens et al. 1993; Fang, Evans, and Landry 2005; Jaworski 1988; Onyemah and Anderson 2009; Sarin and Mahajan 2001) to argue that perceptions of supervisory outcome- and process-oriented actions influence salespeople's primary and secondary appraisals, respectively. Next, we propose that salespeople's performance orientation moderates the influence of these perceived supervisory actions. Finally, we hypothesize that primary and secondary appraisals of salespeople influence their change implementation behaviors and change-related outcomes (see Figure 2).

\section{PERCEIVED SUPERVISORY ACTIONS AND SALESPEOPLE'S APPRAISALS}

\section{Perceived Supervisory Outcome-Oriented Actions}

Outcome risks refer to negative consequences that a salesperson may face upon implementing a strategic change. For example, in our context, if a salesperson's customers begin placing orders on the Internet rather than through her, she might end up earning less in sales commissions. We define "outcome risk containment" as the extent to which a supervisor contains or limits a salesperson's potential losses from successful implementation of a strategic change. In essence, it represents a transfer of risk from a salesperson to the firm (e.g., Bergen, Dutta, and Walker 1992; Sarin and Mahajan 2001) and creates an economic safety net for a salesperson. Supervisors can create this economic safety net by, for example, assuring salespeople they 
will receive a minimum level of commissions even after their customers have migrated to the Internet. Prior research suggests that minimizing outcome risks plays a crucial role in helping affected participants embrace a change (e.g., Edmondson, Bohmer, and Pisano 2001; Lazarus and Folkman 1984). When salespeople believe that adverse effects on their compensation will be limited (e.g., by having an assured base salary), they are likely to appraise the effect of the strategic change on them more favorably (i.e., have a more favorable primary appraisal).

$\mathrm{H}_{1}$ : The greater the perceived outcome risk containment, the more favorable is a salesperson's primary appraisal.

We define "outcome reward emphasis" as the extent to which a supervisor emphasizes rewards associated with a salesperson's successful implementation of a strategic change (see Challagalla and Shervani 1996). These rewards include recognition, promotional opportunities, and takehome pay. Both stress theory (Kahn and Byosiere 1998) and the change management literature emphasize the importance of external rewards for employees coping with stress and implementing change. When employees perceive the linkages between change-related outcome performance and rewards as tenuous, it leads to employee stress and unfavorable assessments of the impact of strategic change on themselves (e.g., Peter and Siegrist 1997; Siegrist 1995; Van Vegchel et al. 2002). In contrast, when supervisors clarify financial and nonfinancial rewards associated with changerelated outcome performance, it sends a strong signal that they value the implementation of change and will reward it. Furthermore, when employees perceive a clear link between change-related outcome performance and outcome rewards, employees such as salespeople are likely to view implementing the change as being personally beneficial - that is, have a more favorable primary appraisal (Klein and Sorra 1996).

$\mathrm{H}_{2}$ : The greater the perceived outcome reward emphasis, the more favorable is a salesperson's primary appraisal.

\section{Perceived Supervisory Process-Oriented Actions}

We define "process risk containment" as the extent to which a supervisor contains or limits a salesperson's potential losses while engaged in efforts directed at implementing a strategic change. This entails, for example, tolerating seemingly obvious questions and forgiving mistakes such as unintentionally providing customers with inaccurate information about transacting on the Internet. The prospect of losing credibility and reputation, or otherwise being penalized for such weaknesses and mistakes, can keep a salesperson from implementing the change effort (see Kohli and Jaworski 1990). In support of this line of thinking, Huy (1999) suggests that people who perceive mistakes during change implementation to be "risky" tend to exhibit greater stress, procrastination, and avoidance of the change.

Process risk containment creates a climate of psychological safety for salespeople. When salespeople perceive the environment to be safe, it encourages them to experiment and learn how to deal with the strategic change without fear of retribution and negative consequences (e.g., Edmondson 1999; Sarin and Mahajan 2001). This is likely to help salespeople learn and develop their ability to deal with the strategic change. In turn, this is likely to make them more confi- dent about being able to deal with the impact of the change on themselves - in other words, have a more favorable secondary appraisal (see Edmondson, Bohmer, and Pisano 2001).

$\mathrm{H}_{3}$ : The greater the perceived process risk containment, the more favorable is a salesperson's secondary appraisal.

We define "process reward emphasis" as the extent to which a supervisor emphasizes rewards for a salesperson's efforts directed at implementing a strategic change (see Challagalla and Shervani 1996). When salespeople perceive their supervisors linking rewards such as recognition or commendations to desired behaviors, it sends a clear signal that supervisors care about the salespeople engaging in productive behaviors that enable them to implement the change successfully. This is likely to encourage salespeople to focus on their behaviors and abilities in a more deliberate and thoughtful manner and learn and develop ideas for more effectively implementing the change and dealing with its impact. In turn, this is likely to increase salespeople's confidence in their ability to deal with impact of the change on themselves - in other words, lead to more favorable secondary appraisals.

$\mathrm{H}_{4}$ : The greater the perceived process reward emphasis, the more favorable is a salesperson's secondary appraisal.

\section{MODERATING EFFECTS OF PERFORMANCE ORIENTATION}

Performance orientation (PO) refers to the extent to which a salesperson wants to perform well on metrics that others consider important (Ahearne et al. 2010; Kohli, Shervani, and Challagalla 1988; Sujan, Weitz, and Kumar 1994; Yeo et al. 2009). Salespeople with higher PO view performing well on important metrics as a means to attaining extrinsic rewards that they value more. Such salespeople are more responsive to supervisory messages and directives relating to the attainment of extrinsic rewards (Dweck and Leggett 1988; Harris, Mowen, and Brown 2005). In general, therefore, we expect the effects of the four perceived supervisory actions discussed previously to be stronger for salespeople with a higher PO, as discussed next.

\section{Perceived Outcome Risk Containment and Outcome Reward Emphasis}

When salespeople perceive supervisors' outcome risk containment to be high, it assures the salespeople of a certain level of benefits (e.g., compensation) and thus likely leads them to appraise the impact of a strategic change on themselves more favorably $\left(\mathrm{H}_{1}\right)$. Salespeople with a higher PO value these benefits to a greater extent because of their greater extrinsic orientation. Therefore, higher perceived outcome risk containment is likely to improve the primary appraisal of higher-PO salespeople to a greater extent than that of lower-PO salespeople. In other words, the effect of perceived outcome risk containment on salespeople's primary appraisals is likely to be greater among salespeople with higher PO.

Similarly, we argued previously that supervisory outcome reward emphasis links salespeople's rewards (e.g., pay, recognition) to successful change implementation and thus likely leads salespeople to appraise the impact of a strategic 
change on themselves more favorably $\left(\mathrm{H}_{2}\right)$. Again, because salespeople with a higher PO value these rewards to a greater extent, the effect of perceived outcome reward emphasis on salespeople's primary appraisals is likely to be greater among salespeople with a higher PO.

$\mathrm{H}_{5}$ : The effect of perceived outcome risk containment on salespeople's primary appraisal is greater for salespeople with a higher PO.

$\mathrm{H}_{6}$ : The effect of perceived outcome reward emphasis on salespeople's primary appraisal is greater for salespeople with a higher PO.

\section{Perceived Process Risk Containment and Process Reward} Emphasis

Supervisory process risk containment limits negative repercussions (e.g., poor performance evaluations, negative feedback) on salespeople if they make mistakes as they go about implementing a strategic change. Thus, perceived process risk containment provides a safe environment in which salespeople can experiment and learn and thus likely leads to greater confidence in their ability to deal with the impact of change on them $\left(\mathrm{H}_{3}\right)$. Because higher-PO salespeople are more sensitive to poor performance evaluations, limiting the fear of negative evaluations is likely to provide them with greater encouragement to experiment and learn, leading to greater increase in confidence in their own ability (see Dweck and Leggett 1988; Janssen and Yperen 2004). In other words, the effect of perceived supervisory process risk containment on salespeople's secondary appraisals is likely to be greater for salespeople with a higher PO.

As we argued previously, perceived process reward emphasis highlights rewards (e.g., recognition, commendation) to be realized from implementing a strategic change and focuses salespeople's attention on learning ideas for dealing with the change and its impact on them. In turn, this is expected to lead to greater confidence in their ability to deal with the impact of change on themselves $\left(\mathrm{H}_{4}\right)$. Because higher-PO salespeople value rewards such as recognition and commendation to a greater extent, they are likely to pay greater attention to learning ideas for dealing with the change and thus improve confidence in their abilities to a greater extent. Put differently, the effect of perceived supervisory process reward emphasis on salespeople's secondary appraisals is likely to be greater for salespeople with a higher PO.

$\mathrm{H}_{7}$ : The effect of perceived process risk containment on salespeople's secondary appraisal is greater for salespeople with a higher PO.

$\mathrm{H}_{8}$ : The effect of perceived process reward emphasis on salespeople's secondary appraisal is greater for salespeople with a higher PO.

\section{SALESPERSON PRIMARY AND SECONDARY APPRAISALS AND CHANGE IMPLEMENTATION}

Salespeople with favorable primary appraisals view a strategic change as having a beneficial impact on them and thus are likely to be more motivated to engage in behaviors directed at implementing the strategic change. Similarly, salespeople with favorable secondary appraisals view themselves as being capable of dealing with the impact of the strategic change on them and thus are likely to exert greater effort in implementing the strategic change (Kahn and Byosiere 1998; Lafferty and Griffin 2006; Lazarus and Folkman 1984). In turn, we expect salespeople's change implementation behaviors to lead to change implementation outcomes (moving customers to transacting business on the Internet).

$\mathrm{H}_{9}$ : The more favorable a salesperson's primary appraisal, the greater are the change implementation behaviors.

$\mathrm{H}_{10}$ : The more favorable a salesperson's secondary appraisal, the greater are the change implementation behaviors.

$\mathrm{H}_{11}$ : The greater the change implementation behaviors, the greater are the change implementation outcomes.

The model in Figure 2 can be interpreted as involving mediation of effects by primary and secondary appraisals. That is, perceptions of supervisory actions affect salespeople's primary and secondary appraisals, which in turn affect salespeople's change implementation behaviors and outcomes. We empirically assess these mediation effects in the "Analyses" and "Results" sections.

\section{METHOD}

\section{Study Context and Data Collection}

Data for the study were collected at the individual level from salespeople of a Fortune 500 company. The company is an industrial distributor with revenues in excess of several billion dollars. It sells more than 500,000 products to more than a million customers. The company's decision to adopt the Internet as its primary sales channel constituted a major change in its strategy, particularly because it was among the earliest in its industry to do so. The company has more than 600 sales branches worldwide, $50 \%$ of which are in the United States. Salespeople affiliated with branches are responsible for generating sales, processing orders, and providing customer service.

We asked three senior vice presidents of the company to write to 234 branch managers to inform them of the purpose of the study and request their cooperation. Next, each branch manager was forwarded individualized packets for onward distribution to salespeople in their branches. The vice presidents forwarded 3059 individualized packets. Each packet contained a letter explaining the purpose of the study, a questionnaire, and a prepaid business reply envelope. The letter directed participants to return their responses directly to the researchers in the reply envelope. To ensure accurate responses, salespeople were promised complete confidentiality. Reminders were sent to all salespeople through the branch managers, two and four weeks after the initial mailing.

Of the initial mailing, 51 surveys were returned because the respondent had moved to a different job or had left the organization. We obtained usable responses from 828 salespeople, for a final response rate of $27.5 \%$. These respondents represented 204 different branches across the United States. We compared the responses and demographic characteristics of the first 100 respondents with the last 100 respondents and found no significant differences in means of the responses on the study constructs or demographics such as age, education, tenure, and sex. This suggests that nonresponse bias is unlikely to be an issue (Armstrong and Overton 1977).

Overall, $71 \%$ of the respondents are male, and $87 \%$ are between the ages of 21 and 50 years. These demographics 
are representative of the composition of the sales force. On average, respondents have 9.7 years of experience at the company, of which 6.1 years are in the sales profession. They have an average of 15 years of education.

\section{Measures}

The level of analysis for this study is the individual salesperson, and thus, we measured all variables at the individual level. We used existing scales when possible, but for some constructs, scales were either unavailable or had limited applicability to the study's context. Therefore, it was necessary to adapt some of the existing scales and develop new ones. Appendix A provides details of the scales used and their sources.

Because salespeople reported their sales managers' outcome- and process-oriented actions, our measures reflect the salesperson's perceptions of supervisory actions. Salespeople also provided information on their own primary and secondary appraisals, as well as change implementation behaviors and outcome. We also obtained data on six control variables to limit threat to the study's findings from unobserved heterogeneity and rule out alternative explanations (see Ye, Marinova, and Singh 2007). These variables include salesperson education, salesperson job tenure, the technological sophistication of a salesperson's customers, customers' relationship commitment to a salesperson, supervisory framing of the change, and supervisory process flexibility.

\section{Measure Validation}

Pretesting. We pretested the study instrument at two branch offices of the company in two stages before final administration. First, we provided a draft of the questionnaire to seven salespeople at one branch office. They filled out the questionnaire individually in the presence of one of the researchers and identified ambiguous or otherwise problematic scale items. We directed particular attention to the items for the new scales to ensure they were clear and captured the essence of the constructs being measured. On the basis of the inputs received, we eliminated some items, modified others, and added some new items.

Next, we followed a similar process with 19 salespeople at a second branch office. Following this, we asked two senior sales and marketing executives from the participating organization to review the questionnaire and identify any problems related to face validity, phrasing, and/or comprehension. Few difficulties surfaced during these rounds of pretesting, suggesting that the instruments were ready for deployment in the main study.

Measurement model. We used Anderson and Gerbing's (1988) two-step approach to examine the psychometric properties of the measures. In the first step, we performed an exploratory factor analysis on groups of related constructs to investigate their factor structure (Singh and Rhoads 1991). The purpose of this analysis was to determine whether items load significantly on at least one factor (loadings $>.50$ ). We discarded a few items that did not meet this criterion. In the second step, we estimated the measurement model using LISREL 8.80. Appendix A reports the completely standardized loading for each item from the measurement analysis.
Table 1 presents the composite reliability for each construct measure and intercorrelations among the measures. The reflective scales exhibit high reliability (i.e., greater than .70) except for outcome reward emphasis and process risk containment, which are both greater than .60 . The average variance extracted (AVE) for measures of outcome risk containment (.78), process risk containment (.50), process reward emphasis (.62), change implementation behaviors (.53), and change implementation outcome (.69) all meet or exceed the .50 threshold (Fornell and Larcker 1981). The AVE of measures of outcome reward emphasis (.47) and PO (.41) are close to the recommended benchmark.

The completely standardized loadings indicate that in every case, path coefficients from latent constructs to their corresponding manifest indicators are statistically significant at $p<.05$, providing evidence of convergent validity. We conducted two tests of discriminant validity. First, per Bagozzi, Yi, and Phillips (1991), we find evidence of discriminant validity because each correlation between pairs of construct measures is less than 1.0 at the $p<.05$ level. Second, for each pair of measures, the AVE for each measure is greater than the squared correlation between the two measures, providing evidence of discriminant validity. Overall, these results suggest that the measures have acceptable psychometric properties.

\section{ANALYSES}

\section{Data Analysis}

We analyzed the data using two-level hierarchical linear models with the HLM 6.08 software package, which is particularly suited for analyzing data when Level 1 units (i.e., lower-level units such as individual salespersons) are nested within Level 2 units (i.e., higher-level units such as sales branches) (Bryk and Raudenbush 1992). This approach recognizes the partial interdependence of salespeople within the same sales branch, allowing for the examination of both lower- and higher-level variance in the variables (Klein and Kozlowski 2000a, b). For each two-level hierarchical linear model analyzed using HLM 6.08, we estimated the models specified at Levels 1 and 2 simultaneously.

\section{Level of Aggregation}

The predictor variables in the study focus on salespeople's perceptions of supervisory actions, which may vary across salespeople for the same supervisor according to their particular interpersonal interactions with the supervisor. This suggests that data should be analyzed at the individual level. Furthermore, a common approach to determining the appropriate level of aggregation for each predictor variable relies on the proportion of its total variance residing within a group versus between groups (i.e., within a sales branch vs. between sales branches). If a significant amount of the total variance in a variable resides between groups, the variable should be aggregated and analyzed at the higher level (i.e., branch); otherwise, it should be analyzed at the lower level (i.e., individual) (Bliese 2000; Bryk and Raudenbush 1992; Hoffman, Griffin, and Gavin 2000; Klein et al. 2000). Intraclass correlations (ICC) may be used to make this determination because they provide an indication of the decomposition of the total variance in the variable (Bliese 2000; Hoffman, Griffin, and Gavin 2000). 


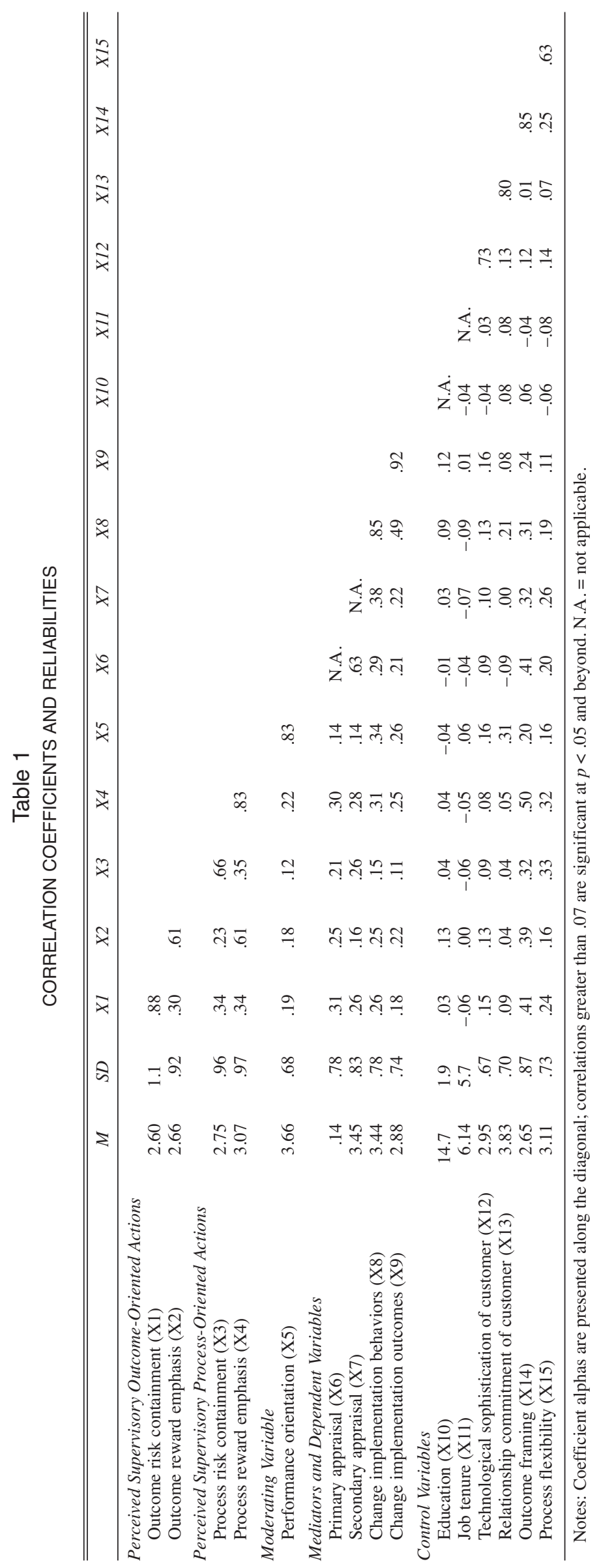


ICC(1) indicates that more than $90 \%$ of the variance for each variable in the study resides within groups (i.e., at the individual salesperson level). Similarly, ICC(2) for all the variables in our study are at or below .25 . Researchers recommend that only variables with ICC(2) values of .70 or higher should be aggregated to a higher level (Bliese 2000; Klein et al. 2000); ICC(2) values lower than .50 make poor candidates for aggregation and thus should be analyzed at the lower level of analysis (Bliese 2000; Klein et al. 2000).

Given the theoretical focus of this study, the finding that a significant amount of the variance in all variables resides within sales branches and the finding that their ICC(2) values fall below the recommended threshold for aggregation, we analyzed all variables in this study at the individual salesperson level. Consequently, we estimated all interaction effects as same-level interactions (i.e., Level $1 \times$ Level 1), and we obtained them by multiplying the relevant (mean-centered) supervisory actions by salespeople's (mean-centered) PO. We used HLM to account for the interdependence among individual salespeople in the same branch.

\section{Model Specification}

The HLM models estimated include the hypothesized effects shown in Figure 2. In addition, the models also include (1) relationships between outcome-oriented supervisory actions and secondary appraisals and (2) relationships between process-oriented supervisory actions and primary appraisals. We included these nonhypothesized relationships to empirically check and account for their presence. Appendix B provides the specific HLM equations used to estimate each of the models. Tables 2 and 3 report the results obtained from estimating these models. Appendix B also presents the HLM equations used for the tests of mediation by primary and secondary appraisals, along with the distributional and statistical assumptions underlying the HLM models. Table 4 reports the results of the tests of mediation.

\section{Common Method Variance}

We follow Ye, Marinova, and Singh's (2007) approach to test for common method bias. Specifically, we estimate a common method factor (CMF) in which the manifest items load onto the $\mathrm{CMF}$ in addition to their latent constructs. Furthermore, in line with Ye, Marinova, and Singh (2007) and Lindell and Whitney (2001), we introduce a new construct (training timing) into the model. In addition, to partial out the variance attributed to the common factor, we include the estimated CMF factor as a predictor variable in each of the structural equations estimated.

Because direct paths are more susceptible to common method bias, we estimate the direct paths while controlling for CMF (Ye, Marinova, and Singh 2007). The main effects findings are consistent with those of the HLM analysis reported in Tables 2 and 3. The robustness of the results after controlling for $\mathrm{CMF}$ provides for greater confidence in our results.

\section{RESULTS}

Tables 2 and 3 report the fixed effects and random effects obtained from the HLM estimation. Tables 2 and 3 also provide the HLM equation numbers in Appendix B corresponding to each set of results (e.g., Equation B1). Overall, the models explain $54 \%$ of Level 1 variance in primary appraisals (i.e., perceived impact of the strategic change on self) and $72 \%$ of Level 1 variance in secondary appraisals (i.e., perceived ability to deal with the impact of the change).

\section{Main Effects of Perceived Outcome-Oriented Supervisory Actions}

We find that perceived outcome risk containment is strongly related to salespeople's primary appraisals $(\gamma=.09$, $p \leq .01)$, in support of $\mathrm{H}_{1}$. Likewise, $\mathrm{H}_{2}$ is supported because perceived outcome reward emphasis has a statistically significant effect on primary appraisals $(\gamma=.05, p \leq$ $.05)$. Although not hypothesized, surprisingly, perceived outcome reward emphasis has a statistically significant, negative influence $(\gamma=-.10, p \leq .01)$ on salespeople's secondary appraisals. Perceived outcome risk containment, however, does not appear to affect salespeople's secondary appraisals.

\section{Main Effects of Perceived Process-Oriented Supervisory Actions}

Both perceived process risk containment $(\gamma=.06, p \leq .01)$ and perceived process reward emphasis $(\gamma=.11, p \leq .01)$ have a strong positive influence on secondary appraisals, in support of $\mathrm{H}_{3}$ and $\mathrm{H}_{4}$. Neither of the two perceived processoriented actions is related to salespeople's primary appraisals. More generally, as hypothesized, the aforementioned set of findings indicates that perceptions of supervisory outcomeoriented actions seem to influence salespeople's primary appraisals, whereas perceptions of supervisory processoriented actions seem to influence salespeople's secondary appraisals.

\section{Moderating Effects of Salesperson PO}

Table 2 also presents the results pertaining to tests of the moderating effects of salespeople's PO on the relationships between perceived supervisory actions and salespeople's appraisals of change. Consistent with $\mathrm{H}_{5}, \mathrm{PO}$ has a positive moderating effect on the relationship between perceived outcome risk containment and primary appraisals $(\gamma=.11, p \leq$ $.01)$. However, PO does not moderate the relationship between perceived outcome reward emphasis and salespeople's primary appraisals $(\gamma=.03$, not significant [n.s.]). Thus, whereas our data support $\mathrm{H}_{5}$, they do not support $\mathrm{H}_{6}$.

$\mathrm{H}_{7}$ predicts that $\mathrm{PO}$ moderates the effect of perceived process risk containment on salespeople's secondary appraisals. The hypothesis receives strong support $(\gamma=.07$, $p \leq .01)$. In contrast, $\mathrm{PO}$ seems to have no moderating influence on the relationship between perceived process reward emphasis and salespeople's secondary appraisals $(\gamma=-.06$, n.s.); thus, $\mathrm{H}_{8}$ is not supported. Notably, none of the nonhypothesized moderated paths are significant. More generally, and consistent with the hypotheses, PO tends to moderate the effect of perceived outcome-oriented actions on primary appraisals and the effect of perceived process-oriented actions on secondary appraisals.

\section{Effects of Change Appraisals and Change Implementation Behavior}

Table 3 indicates that the data strongly support the two hypotheses related to the main effects of primary and secondary appraisals on change implementation behavior $\left(\mathrm{H}_{9}\right.$ 
Table 2

HLM RESULTS: RELATIONSHIPS BETWEEN PERCEIVED SUPERVISORY ACTIONS AND SALESPERSONS' CHANGE APPRAISALS

\begin{tabular}{|c|c|c|c|c|}
\hline \multirow[b]{3}{*}{ Independent Variables } & \multicolumn{4}{|c|}{ Dependent Variables } \\
\hline & \multicolumn{2}{|c|}{ Primary Appraisal (Equation B1) } & \multicolumn{2}{|c|}{ Secondary Appraisal (Equation B2) } \\
\hline & Fixed Effects ${ }^{a}(\gamma)$ & Random Effects ${ }^{b, c}(u)$ & Fixed Effects ${ }^{a}(\gamma)$ & Random Effects ${ }^{b, c}(u)$ \\
\hline Intercept & -.02 & $2.86^{* *}$ & $2.68 * * *$ & 1.09 \\
\hline $\begin{array}{l}\text { Main Effects } \\
\text { Outcome risk containment } \\
\text { Outcome reward emphasis } \\
\text { Process risk containment } \\
\text { Process reward emphasis } \\
\text { Performance orientation (PO) }\end{array}$ & $\begin{array}{l}.09 * * * \\
.05 * * \\
.002 \\
.04 \\
.08 * * *\end{array}$ & $\begin{array}{l}.01 \\
.03 \\
.01 \\
.002 \\
.02\end{array}$ & $\begin{array}{l}-.02 \\
-.10 * * * \\
.06 * * * \\
.11 * * * \\
.04\end{array}$ & $\begin{array}{l}.02 * * \\
.04 * * \\
.01 \\
.01 \\
.03\end{array}$ \\
\hline $\begin{array}{l}\text { Level } 1 \text { Interaction Effects } \\
\text { Outcome risk containment } \times \mathrm{PO} \\
\text { Outcome reward emphasis } \times \mathrm{PO} \\
\text { Process risk containment } \times \mathrm{PO} \\
\text { Process reward emphasis } \times \mathrm{PO}\end{array}$ & $\begin{array}{l}. \mathbf{1 1} * * * \\
.03 \\
-.05 \\
.01\end{array}$ & $\begin{array}{l}.04 \\
.06 \\
.03 \\
.08 * *\end{array}$ & $\begin{array}{l}.04 \\
-.02 \\
.07 * * * \\
-.06\end{array}$ & $\begin{array}{l}.03 \\
.04 \\
.02 \\
.12 * * *\end{array}$ \\
\hline $\begin{array}{l}\text { Control Variables } \\
\text { Education } \\
\text { Job tenure } \\
\text { Technological sophistication of customer } \\
\text { Relationship commitment of customer } \\
\text { Outcome framing } \\
\text { Process flexibility } \\
\text { Primary appraisal }\end{array}$ & $\begin{array}{l}-.02 \\
-.001 \\
.05 \\
-.15 * * * \\
.23 * * * \\
.07 * *\end{array}$ & $\begin{array}{l}.002 \\
.001 * \\
.05 * * \\
.09 * * * \\
.02 \\
.01\end{array}$ & $\begin{array}{l}.02 * * \\
-.001 \\
.03 \\
-.01 \\
.01 \\
.11 * * * \\
.60 * * *\end{array}$ & $\begin{array}{l}.002 \\
.00 \\
.02 \\
.03 \\
.01 \\
.03 \\
.04 * *\end{array}$ \\
\hline $\begin{array}{l}\text { Level } 1 \text { - R (variance component) } \\
\text { Level } 1 \text { variance explained }\end{array}$ & & & & \\
\hline
\end{tabular}

$* p \leq .10$.

$* * p \leq .05$.

$* * * p \leq .01$

aFixed effects refer to average of the unstandardized coefficients across groups.

bRandom effects refer to variance of the coefficients across groups.

cSignificance tests for variances were performed using z-tests as Raudenbush and Bryk (2002) recommend.

Notes: Hypothesized relationships are noted in bold. Outcome risk containment, outcome reward emphasis, process risk containment, process reward emphasis, outcome framing, and process flexibility reflect salespersons' perceptions of supervisory actions.

\section{Table 3}

HLM RESULTS: RELATIONSHIPS AMONG SALESPERSONS' CHANGE APPRAISALS, CHANGE IMPLEMENTATION BEHAVIOR, AND CHANGE IMPLEMENTATION OUTCOME

\begin{tabular}{|c|c|c|c|c|}
\hline \multirow[b]{3}{*}{ Independent Variables } & \multicolumn{4}{|c|}{ Dependent Variables } \\
\hline & \multicolumn{2}{|c|}{ Change Implementation Behavior (Equation B3) } & \multicolumn{2}{|c|}{ Change Implementation Outcome (Equation B4) } \\
\hline & Fixed Effects ${ }^{a}(\gamma)$ & Random Effects ${ }^{b, c}(u)$ & Fixed Effects ${ }^{a}(\gamma)$ & Random Effects ${ }^{b, c}(u)$ \\
\hline Intercept & $.60 * * *$ & .43 & $.43 * *$ & .99 \\
\hline $\begin{array}{l}\text { Main Effects } \\
\text { Primary appraisal } \\
\text { Secondary appraisal } \\
\text { Change implementation behavior }\end{array}$ & $\begin{array}{l}.08 * * \\
.28 * * *\end{array}$ & $\begin{array}{l}.03 \\
.03\end{array}$ & $.43 * * *$ & $.05^{* *}$ \\
\hline $\begin{array}{l}\text { Control Variables } \\
\text { Education } \\
\text { Job tenure } \\
\text { PO } \\
\text { Technological sophistication of customer } \\
\text { Relationship commitment of customer }\end{array}$ & $\begin{array}{l}.02 * * \\
-.01 * * \\
.27 * * * \\
.03 \\
.14 * * *\end{array}$ & $\begin{array}{l}.002 \\
.001 \\
.03 \\
.01 \\
.03\end{array}$ & $\begin{array}{l}.03 * * * \\
.01 * \\
.11 * * * \\
.11 * * * \\
-.07 * *\end{array}$ & $\begin{array}{l}.002 \\
.00 \\
.07 * * \\
.02 \\
.02\end{array}$ \\
\hline $\begin{array}{l}\text { Level } 1 \text { - R (variance component) } \\
\text { Level } 1 \text { variance explained }\end{array}$ & & & & \\
\hline
\end{tabular}

$* p \leq .10$.

$* * p \leq .05$.

$* * * p \leq .01$.

aFixed effects refer to average of the unstandardized coefficients across groups.

bRandom effects refer to variance of the coefficients across groups.

cSignificance tests for variances were performed using z-tests as Raudenbush and Bryk (2002) recommend.

Notes: Hypothesized relationships are noted in bold. 
and $\left.\mathrm{H}_{10}\right)(\gamma=.08, p \leq .05 ; \gamma=.28, p \leq .01) . \mathrm{H}_{11}$, which hypothesizes a positive relationship between change implementation behavior and change implementation outcomes, is supported as well $(\gamma=.43, p \leq .01)$. Overall, salespeople's change appraisals (and control variables) explain 36\% of the Level 1 variance in change implementation behaviors, and change implementation behaviors (and control variables) explain $40 \%$ of the Level 1 variance in change implementation outcomes (i.e., salesperson change-related performance).

\section{Tests of Mediation}

The test of mediation that Baron and Kenny (1986) outline suggests that if the direct effects of perceived supervisory actions on salespeople's change implementation behavior are weakened (or made statistically nonsignificant) by the addition of a change appraisal variable, change appraisal may be said to mediate the effects of the perceived supervisory actions on change implementation behavior. The results suggest that primary appraisals partially mediate the main effects of two perceived supervisory actions: outcome risk containment and process reward emphasis (see Table 4). Similarly, we find that secondary appraisals partially medi- ate the main effect of perceived process reward emphasis. Neither perceived outcome reward emphasis nor perceived process risk containment have a direct effect on salespeople's change implementation behavior. The effect of perceived process risk containment is experienced solely through secondary appraisals, and the effect of perceived outcome reward emphasis on change implementation behavior seems to be fully mediated through primary and secondary appraisals.

\section{DISCUSSION}

The present study is among a very small set that examines the influence of frontline supervisors on strategic change implementation. It helps address the criticism that there is a dearth of research on effective marketing strategy implementation (Chimhanzi and Morgan 2005). It adds to recent work in marketing on the role of salespeople (e.g., Ahearne et al. 2010) and frontline employees (e.g., Cadwallader et al. 2010; Ye, Marinova, and Singh 2007) in implementing organizational change.

A significant contribution of this research is the development of a typology of four supervisory actions using the

Table 4

HLM RESULTS: TESTS OF MEDIATION BY PRIMARY AND SECONDARY APPRAISALS

\begin{tabular}{|c|c|c|c|c|c|c|}
\hline \multirow[b]{3}{*}{ Independent Variables } & \multicolumn{6}{|c|}{$\begin{array}{c}\text { Dependent Variables: } \\
\text { Change Implementation Behavior }\end{array}$} \\
\hline & \multicolumn{2}{|c|}{$\begin{array}{l}\text { Direct Effects } \\
\text { (Equation B5) }\end{array}$} & \multicolumn{2}{|c|}{$\begin{array}{c}\text { Test of Mediation by } \\
\text { Primary Appraisal (Equation B6) }\end{array}$} & \multicolumn{2}{|c|}{$\begin{array}{c}\text { Test of Mediation by } \\
\text { Secondary Appraisala (Equation B7) }\end{array}$} \\
\hline & $\begin{array}{c}\text { Fixed } \\
\text { Effects }^{b}(\gamma)\end{array}$ & $\begin{array}{c}\text { Random } \\
\text { Effects }, d(u)\end{array}$ & $\begin{array}{c}\text { Fixed } \\
\text { Effects }^{b}(\gamma)\end{array}$ & $\begin{array}{c}\text { Random } \\
\text { Effects }{ }^{c}, d(u)\end{array}$ & $\begin{array}{c}\text { Fixed } \\
\text { Effects }^{b}(\gamma)\end{array}$ & $\begin{array}{c}\text { Random } \\
\text { Effectsc, } d(u)\end{array}$ \\
\hline Intercept & $2.32 * * *$ & .95 & $2.12 * * *$ & .30 & $1.57 * * *$ & .34 \\
\hline $\begin{array}{l}\text { Main Effects } \\
\text { Outcome risk containment } \\
\text { Outcome reward emphasis } \\
\text { Process risk containment } \\
\text { Process reward emphasis } \\
\text { PO } \\
\text { Primary appraisal } \\
\text { Secondary appraisal }\end{array}$ & $\begin{array}{l}.07 * * * \\
.03 \\
-.02 \\
.10 * * * \\
.28 * * *\end{array}$ & $\begin{array}{l}.03 * * \\
.03 \\
.01 \\
.02 \\
.06^{* *}\end{array}$ & $\begin{array}{l}.05 * * \\
.03 \\
-.01 \\
.09 * * * \\
.25 * * * \\
.13 * * *\end{array}$ & $\begin{array}{l}.03 * * * \\
.02 \\
.01 \\
.02 \\
.05^{* *} \\
.03^{*}\end{array}$ & $\begin{array}{l}.05 * * \\
.05 * \\
-.03 \\
.07 * * \\
.22 * * * \\
-.01 \\
.24 * * *\end{array}$ & $\begin{array}{l}.03 * * * \\
.01 \\
.003 \\
.02 \\
.04 \\
.04 \\
.005\end{array}$ \\
\hline $\begin{array}{l}\text { Interaction Effects } \\
\text { Outcome risk containment } \times \mathrm{PO} \\
\text { Outcome reward emphasis } \times \mathrm{PO} \\
\text { Process risk containment } \times \mathrm{PO} \\
\text { Process reward emphasis } \times \mathrm{PO}\end{array}$ & $\begin{array}{l}.10 * * * \\
-.10 * * \\
-.03 \\
.08 * *\end{array}$ & $\begin{array}{l}.02 \\
.03 \\
.02 \\
.04\end{array}$ & $\begin{array}{c}.09 * * * \\
-.08 * * \\
-.04 \\
.07 *\end{array}$ & $\begin{array}{l}.02 \\
.05 \\
.02 \\
.05\end{array}$ & $\begin{array}{c}.07 * * \\
-.07 * \\
-.07 * * \\
.08 * *\end{array}$ & $\begin{array}{l}.03 \\
.07 * \\
.01 \\
.04\end{array}$ \\
\hline $\begin{array}{l}\text { Control Variables } \\
\text { Education } \\
\text { Job tenure } \\
\text { Technological sophistication of customer } \\
\text { Relationship commitment of customer } \\
\text { Outcome framing } \\
\text { Process flexibility }\end{array}$ & $\begin{array}{l}.01 \\
-.01 \\
.04 \\
.13 * * * \\
.09 * * * \\
.07 * *\end{array}$ & $\begin{array}{l}.003 \\
.001^{* * *} \\
.01 \\
.03^{*} \\
.04^{*} \\
.04^{*}\end{array}$ & $\begin{array}{l}.02 * \\
-.005 \\
.03 \\
.14 * * * \\
.07 * * \\
.06 * *\end{array}$ & $\begin{array}{l}.002 \\
.001 * * \\
.01 \\
.04^{* *} \\
.03^{* *} \\
.03\end{array}$ & $\begin{array}{l}.02 * \\
-.004 \\
.01 \\
.13 * * * \\
.07 * * * \\
.03\end{array}$ & $\begin{array}{l}.001 \\
.001 * * \\
.01 \\
.03 \\
.03 \\
.02\end{array}$ \\
\hline $\begin{array}{l}\text { Level } 1 \text { - R (variance component) } \\
\text { Level } 1 \text { variance explained }\end{array}$ & & & & & & \\
\hline
\end{tabular}

\footnotetext{
$* p \leq .10$.
}

$* * p \leq .05$

$* * * p \leq .01$.

aThe fixed effects in column 3 (primary appraisal) act as a reference for this test.

bFixed effects refer to average of the unstandardized coefficients across groups.

cRandom effects refer to variance of the coefficients across groups.

dSignificance tests for variances were performed using z-tests as Raudenbush and Bryk (2002) recommend.

Notes: A coefficient in bold indicates that it was reduced or became statistically insignificant after we introduced primary appraisal (or secondary appraisal) as a predictor in an equation. This provides evidence of the mediating role of primary (or secondary) appraisal between the independent variable associated with the coefficient and change implementation behavior. Outcome risk containment, outcome reward emphasis, process risk containment, process reward emphasis, outcome framing, and process flexibility reflect salespersons' perceptions of supervisory actions. 
dimensions of outcome versus process and risk versus reward: (1) outcome risk containment, (2) outcome reward emphasis, (3) process risk containment, and (4) process reward emphasis. We show that perceptions of supervisory outcome-oriented actions influence salespeople's primary appraisals, while perceptions of supervisory process-oriented actions influence salespeople's secondary appraisals.

Surprisingly, whereas perceived outcome reward emphasis affects salespeople's primary appraisals as hypothesized, it seems to have a negative effect on secondary appraisals. These findings are of particular interest from a managerial perspective because they suggest that financially expensive supervisory interventions linking rewards to the successful outcome of change implementation may yield mixed results. Our findings suggest that in a change implementation context, salespeople tend to respond more favorably to risk mitigation than to reward enhancement actions. These findings are consistent with prospect theory (Kahneman and Tversky 1979), which suggests that when evaluating choices under uncertain conditions (e.g., implementing strategic change), loss avoidance looms larger than gain seeking. The findings are also consistent with research on reward structures, which indicates that people prefer to not have their rewards linked to outcomes when the outcomes are risky or uncertain (e.g., Sarin and Mahajan 2001).

This study also focuses on two types of risks in change implementation. While the risk of strategic change outcomes is well recognized, much less attention has been paid to the risk inherent in the process of change implementation itself. Our results show that by addressing salespeople's process risk and by tying rewards to diligent efforts undertaken by salespeople, supervisors can encourage salespeople to learn and implement a change more successfully.

Notably, we find that perceived (outcome and process) risk containment has a greater influence on appraisals of salespeople with a higher PO, but the effects of (outcome and process) reward emphases are invariant across salespeople's $\mathrm{PO}$. In tandem with the findings noted here, this suggests that successful implementation of strategic change may depend not merely or even primarily on giving rewards to salespeople for implementing change but also on limiting salespeople's risks and recognizing them for their changerelated efforts.

\section{LIMITATIONS AND RESEARCH DIRECTIONS}

Although we provide empirical evidence that is consistent with hypothesized effects of supervisory actions, our analysis does not explicitly incorporate the temporal dynamics involved; rather, we relate cross-sectional variability in perceived supervisory actions to salespeople's appraisals and behaviors as predicted according to theory. A key limitation of this approach is that it does not provide evidence of the underlying processes as strongly as a dynamic analysis using longitudinal data.

The study includes a relatively small number of responses within a branch, which may have resulted in a larger proportion of the variance residing within groups than between groups. A larger number of responses within each branch would lead to greater confidence in the results. Although this is a limitation, it is not uncommon for the within-group variance to be much larger than the betweengroup variance in samples with fewer than 25 people per group (Klein and Kozlowski 2000a). Simulations conducted by Maas and Hox (2005) suggest that a sample size of 50 groups with an average of 5 (or even fewer) people within groups provides sufficient power for testing fixed effects (though not random effects), which are the focus of our hypotheses. Furthermore, Hoffman, Griffin, and Gavin (2000, p. 496) note that these requirements are somewhat compensatory: If the number of Level 2 units (i.e., groups) is larger, it can offset the required number of Level 1 units (i.e., individual salespeople) within groups. The present study uses a relatively large number of Level 2 units: 204 groups (branches) and 828 individual salespeople, with an average of 4.05 people within each group. This suggests that the average number of people within groups is unlikely to be a major issue.

Another limitation of the study is that although it employs data from 828 salespeople, they are from a single firm. Although this allows for important controls, it would be useful to study the research issues in firms with different characteristics and in different industries to assess the generalizability of the findings. Finally, the study uses subjective measures of change implementation. It would be instructive to replicate and extend these results using objective measures of change implementation.

There are several avenues for additional research on this important topic. We find that perceived supervisory outcome framing, a control variable in the study, is strongly related to salespeople's primary appraisal. It would be worthwhile to investigate the role of supervisory framing more comprehensively in further research. For example, what are the effects of framing a strategic change in positive terms (reflecting the benefits to be gained from successful change implementation) versus negative terms (reflecting the harm that may be caused by unsuccessful change implementation or failure to change)? It is unclear which of the two frames would be more effective in encouraging salespeople to implement a change in marketing strategy. Similarly, it would be useful to study the relative effectiveness of supervisors pitching a change in terms of the benefits or losses to salespeople personally versus to their firms.

Our findings suggest that the perceptions of the same supervisory action evoke differential responses from highversus low-PO salespeople. It would be useful to identify more comprehensively the role of individual-level variables in determining the effectiveness of alternative supervisory framing strategies. For example, do salespeople's POs or loci of control moderate the influence of positive versus negative supervisory framings? Do salespeople's learning orientations moderate the effects of positioning a change in terms of benefits and losses to salespeople versus their firms? These aspects of supervisory framing offer opportunities for further investigation.

Prior literature views primary and secondary appraisals as independent constructs: Both can occur independently and virtually simultaneously (e.g., Lazarus and Folkman 1984; Lowe et al. 2003). Our empirical results suggest that there is a statistically significant and substantial relationship between primary and secondary appraisals (see Table 2). It is possible that the relationship found in this study is due to the common response format used to measure primary and secondary appraisals; it would be useful to test the relationship using measures with different response formats in fur- 
ther research. It is also possible that in contexts such as the current study (e.g., strategic change), there may be a theoretical relationship between the two constructs (e.g., primary appraisals may be antecedents of secondary appraisals). It would be useful to conduct a deeper investigation of the nature of the relationship between the two constructs in further research.

Several other questions worthy of investigation also surface in this study. For example, why do some salespeople welcome the opportunity to implement a change, whereas others shun change? Are there managerially actionable

\section{Appendix A \\ MEASURES}

\begin{tabular}{lc}
\hline \hline Construct Items & Loadinga \\
\hline
\end{tabular}

\section{Outcome Risk Containment}

1. My supervisor assured me of a base level of compensation even if my customers ordered online.

2. My company policy assured all salespeople of a minimum level of compensation as customers started to buy online.

Outcome Reward Emphasis (Based on Jaworski and Kohli 1991)

1. Salespeople were recognized by the organization if they performed well on their Internet sales targets.

2. Promotion opportunities were more likely to open up for salespeople if they performed well on their Internet sales targets.

3. My total take-home pay was dependent on how much sales I generated on the Internet. ${ }^{b}$

Process Risk Containment (Based on Edmondson 1999)

1. My supervisor often assured me that making mistakes was a normal part of learning about online sales.

2. My supervisor encouraged me to engage in trial and error in learning about online sales.

3. Any mistakes I made in getting customers to order on line were held against me. (R) ${ }^{\mathrm{b}}$

4. There were no repercussions when others in my position made errors in moving customers online. (R) ${ }^{\mathrm{b}}$

Process Reward Emphasis (Based on Jaworski and Kohli 1991)

1. My supervisor commended salespeople when s/he saw them making efforts to migrate customers online.

2. My manager recognized salespeople who had taken the time to learn our Internet sales system.

3. My manager acknowledged salespeople who helped their coworkers get up to speed on our online strategy.

Performance Orientation (Based on Sujan, Weitz, and Kumar 1994)

1. I feel very good when I know I have outperformed my peers.

2. It is very important to me that my supervisor sees me as a productive salesperson.

3. I very much want my peers to consider me to be good at selling.

4. I evaluate myself using my supervisor's criteria.

5. It is important for me to perform better than my peers.

6. I always try to communicate my sales accomplishments to my supervisor.

7. I spend a lot of time thinking about how my performance compares with that of my peers.

Primary Appraisalc (Formative Scale; Based on Teas 1981)

The impact this change is likely to have on ...

1. Your workload.

2. Your opportunities to learn new things.

3 . Your relationships with your customers

4. Yhe amount of flexibility you have in your job.

5. Your relationship with your supervisor.

6 . The nature of the work you do.

7. Your total dollar compensation (i.e., salary, commission, bonus, etc.).

8 . Your status/position in the organization.

9. Your chances of advancement in this organization.

10. Your job security. ways of a priori identifying the majority of salespeople who are likely to neither embrace nor shun the change but adopt an indifferent or apathetic "wait and see" attitude? What actions can supervisors take to convert such a silent majority to increase the acceptance of the change and speed up the change implementation effort? It would also be useful to address related issues in further research using complementary methods (e.g., observational techniques, longitudinal designs) and in a diverse set of organizations (e.g., small vs. large firms, firms with salespeople with short vs. long tenures).

\section{Appendix A} CONTINUED

\begin{tabular}{ll}
\hline \hline Construct Items & Loadinga \\
\hline Secondary Appraisald (Formative Scale; Based on Teas 1981)
\end{tabular}

Secondary Appraisald (Formative Scale; Based on Teas 1981)

How confident are you about your ability to deal with any impact this change is likely to have on ...

1. Your workload.

2. Your opportunities to learn new things.

3. Your relationships with your customers.

4. The amount of flexibility you have in your job.

5 . Your relationship with your supervisor.

6. The nature of the work you do.

7. Your total dollar compensation (i.e., salary, commission, bonus, etc.).

8. Your status/position in the organization.

9. Your chances of advancement in this organization.

10. Your job security.

Change Implementation Behaviors

1. I help my customers learn more about our online capabilities.

2. I make it a priority to learn the details of our Internet sales system.

3. I try to help my coworkers with questions about our Internet system as much as possible.

I seek advice from others who have successfully migrated customers to online purchasing.

5. I make every effort to help implement our Internet strategy.

Change Implementation Outcomese (Based on Sujan, Weitz, and Kumar 1994)

1. The number of customers you have persuaded to order from your company website.

2 . The percentage of your total sales that are generated online.

3 . The rate at which you are growing the Internet component of your overall sales.

4. The dollar amount of sales generated by you online.

5. Meeting Internet sales targets.

Relationship Commitment of Customer

1. The kinds of customers I deal with see salespeople as a resource that cannot be replaced by technology.

2. Most of my customers are interested in maintaining a close relationship with me.

3. Even if my customers could make all their purchases online, they would still like to retain their relationship with me.

4. My customers believe that I can deliver more value to them than the Internet.

Technological Sophistication of Customer

1. The kind of customers I deal with know a lot about technology.

2. Many of my customers use the Internet to obtain information relevant to their business.

3. My customers use computers to manage virtually all aspects of their business.

4. In general, my customers seem to be comfortable with purchasing on the Internet. 
Level 2:

$$
\begin{aligned}
\beta_{0 \mathrm{j}} & =\gamma_{00}+\mathrm{u}_{0 \mathrm{j}}, \\
\beta_{\mathrm{mj}} & =\gamma_{\mathrm{m} 0}+\mathrm{u}_{\mathrm{mj}}, \\
\mathrm{m} \in \mathrm{N} & =\{1,2, \ldots, 16\},
\end{aligned}
$$

where SECAPP = secondary appraisal and all other notations are the same as before. Table 2 reports the results obtained from estimating the HLM models outlined in Equations B1 and B2 .

Relationships Among Salespeople's Change Appraisals, Change Implementation Behavior, and Change Implementation Outcome

$\mathrm{H}_{9}$ and $\mathrm{H}_{10}$ examine the effect of primary and secondary appraisals on change implementation behavior, and we tested them by estimating the following HLM model:

(B3) Level 1:

$$
\begin{aligned}
\text { CHGBEH }_{i j}= & \beta_{0 j}+\beta_{1 j}\left(\text { PRIMAPP }_{i j}\right)+\beta_{2 j}\left(\text { SECAPP }_{i j}\right) \\
& +\beta_{3 j}\left(\text { EDUC }_{i j}\right)+\beta_{4 j}\left(\text { TENURE }_{i j}\right)+\beta_{5 j}\left(\text { PO }_{i j}\right) \\
& +\beta_{6 j}\left(\text { TECHSOPH }_{i j}\right)+\beta_{7 j}\left(\text { RELCOMIT }_{i j}\right)+r_{i j}
\end{aligned}
$$

Level 2:

$$
\begin{gathered}
\beta_{0 \mathrm{j}}=\gamma_{00}+\mathrm{u}_{0 \mathrm{j}}, \\
\beta_{\mathrm{mj}}=\gamma_{\mathrm{m} 0}+\mathrm{u}_{\mathrm{mj}}, \\
\mathrm{m} \in \mathrm{N}=\{1,2, \ldots, 7\},
\end{gathered}
$$

where $\mathrm{CHGBEH}=$ change implementation behavior and all other notations are the same as before.

$\mathrm{H}_{11}$ hypothesizes a relationship between change implementation behavior and change implementation outcome. We tested it by estimating the following HLM model:

(B4) Level 1:

$$
\begin{aligned}
\text { CHGOUT }_{i j}= & \beta_{0 j}+\beta_{1 j}\left(\text { CHGBEH }_{i j}\right)+\beta_{2 j}\left(\text { EDUC }_{i j}\right) \\
& +\beta_{3 j}\left(\text { TENURE }_{i j}\right)+\beta_{4 j}\left(\text { PO }_{i j}\right)+\beta_{5 j}\left(\text { TECHSOPH }_{i j}\right) \\
& +\beta_{6 j}\left(\text { RELCOMIT }_{i j}\right)+r_{i j}
\end{aligned}
$$

Level 2:

$$
\begin{gathered}
\beta_{0 \mathrm{j}}=\gamma_{00}+\mathrm{u}_{0 \mathrm{j}}, \\
\beta_{\mathrm{mj}}=\gamma_{\mathrm{m} 0}+\mathrm{u}_{\mathrm{mj}}, \\
\mathrm{m} \in \mathrm{N}=\{1,2, \ldots, 6\},
\end{gathered}
$$

where CHGOUT $=$ change implementation outcome and all other notations are the same as before. Table 3 reports the results obtained from estimating the HLM models outlined in Equations B3 and B4.

\section{Tests of Mediation by Primary and Secondary Appraisals}

We followed the procedure that Baron and Kenny (1986) outline to test whether salespeople's primary and secondary appraisals mediate the effects of the four supervisory actions on salespeople's change implementation behavior. First, we regressed change implementation behavior on the supervisory actions (plus interaction terms, moderator variable, and control variables) directly. We estimated the direct effects of supervisory actions using the following:

(B5) Level 1:

$$
\begin{aligned}
\text { CHGBEH }_{\mathrm{ij}}= & \beta_{0 \mathrm{j}}+\beta_{1 \mathrm{j}}\left(\text { OUTRISK }_{\mathrm{ij}}\right)+\beta_{2 \mathrm{j}}\left(\text { OUTREW }_{\mathrm{ij}}\right) \\
& +\beta_{3 \mathrm{j}}\left(\text { PRORISK }_{\mathrm{ij}}\right)+\beta_{4 \mathrm{j}}\left(\text { PROREW }_{\mathrm{ij}}\right)+\beta_{5 \mathrm{j}}\left(\text { PO }_{\mathrm{ij}}\right) \\
& +\beta_{6 \mathrm{j}}\left(\text { OUTRISK }_{\mathrm{ij}} \times \text { PO }_{\mathrm{ij}}\right)+\beta_{7 \mathrm{j}}\left(\text { OUTREW }_{\mathrm{ij}} \times \mathrm{PO}_{\mathrm{ij}}\right) \\
& +\beta_{8 \mathrm{j}}\left(\text { PRORISK }_{\mathrm{ij}} \times \text { PO }_{\mathrm{ij}}\right)+\beta_{9 \mathrm{j}}\left(\text { PROREW }_{\mathrm{ij}} \times \text { PO }_{\mathrm{ij}}\right) \\
& +\beta_{10 \mathrm{j}}\left(\text { EDUC }_{\mathrm{ij}}\right)+\beta_{11 \mathrm{j}}\left(\text { TENURE }_{\mathrm{ij}}\right) \\
& +\beta_{12 \mathrm{j}}\left(\text { TECHSOPH }_{\mathrm{ij}}\right)+\beta_{13 \mathrm{j}}\left(\text { RELCOMIT }_{\mathrm{ij}}\right) \\
& +\beta_{14 \mathrm{j}}\left(\text { OUTFRAME }_{\mathrm{ij}}\right)+\beta_{15 \mathrm{j}}\left(\text { PROFLEX }_{\mathrm{ij}}\right)+\mathrm{r}_{\mathrm{ij}}
\end{aligned}
$$

Level 2:

$$
\begin{gathered}
\beta_{0 \mathrm{j}}=\gamma_{00}+\mathrm{u}_{0 \mathrm{j}}, \\
\beta_{\mathrm{mj}}=\gamma_{\mathrm{m} 0}+\mathrm{u}_{\mathrm{mj}}, \\
\mathrm{m} \in \mathrm{N}=\{1,2, \ldots, 15\} .
\end{gathered}
$$

Next, we added primary appraisal, a potential mediating variable, as a Level 1 predictor to Equation B5 (Baron and Kenny 1986). We estimated the mediating effect of primary appraisal using the model (and determining whether the direct effects of supervisory actions reduce in magnitude or become statistically insignificant):

(B6) Level 1:

$$
\begin{aligned}
\text { CHGBEH }_{i j}= & \beta_{0 \mathrm{j}}+\beta_{1 \mathrm{j}}\left(\text { OUTRISK }_{\mathrm{ij}}\right)+\beta_{2 \mathrm{j}}\left(\text { OUTREW }_{\mathrm{ij}}\right) \\
& +\beta_{3 \mathrm{j}}\left(\text { PRORISK }_{\mathrm{ij}}\right)+\beta_{4 \mathrm{j}}\left(\text { PROREW }_{\mathrm{ij}}\right)+\beta_{5 \mathrm{j}}\left(\mathrm{PO}_{\mathrm{ij}}\right) \\
& +\beta_{6 \mathrm{j}}\left(\text { PRIMAPP }_{\mathrm{ij}}\right)+\beta_{7 \mathrm{j}}\left(\text { OUTRISK }_{\mathrm{ij}} \times \text { PO }_{\mathrm{ij}}\right) \\
& +\beta_{8 \mathrm{j}}\left(\text { OUTREW }_{\mathrm{ij}} \times \text { PO }_{\mathrm{ij}}\right)+\beta_{9 \mathrm{j}}\left(\text { PRORISK }_{\mathrm{ij}} \times \text { PO }_{\mathrm{ij}}\right) \\
& +\beta_{10 \mathrm{j}}\left(\text { PROREW }_{\mathrm{ij}} \times \text { PO }_{\mathrm{ij}}\right)+\beta_{11 \mathrm{j}}\left(\text { EDUC }_{\mathrm{ij}}\right) \\
& +\beta_{12 \mathrm{j}}\left(\text { TENURE }_{\mathrm{ij}}\right)+\beta_{13 \mathrm{j}}\left(\text { TECHSOPH }_{\mathrm{ij}}\right) \\
& +\beta_{14 \mathrm{j}}\left(\text { RELCOMIT }_{\mathrm{ij}}\right)+\beta_{15 \mathrm{j}}\left(\text { OUTFRAME }_{\mathrm{ij}}\right) \\
& +\beta_{16 \mathrm{j}}\left(\text { PROFLEX }_{\mathrm{ij}}\right)+\mathrm{r}_{\mathrm{ij}}
\end{aligned}
$$

Level 2:

$$
\begin{gathered}
\beta_{0 j}=\gamma_{00}+u_{0 j}, \\
\beta_{m j}=\gamma_{m 0}+u_{m j}, \\
m \in N=\{1,2, \ldots, 16\} .
\end{gathered}
$$

Finally, we similarly assessed the incremental mediating effect of secondary appraisal (beyond that of primary appraisal) by adding secondary appraisal as a Level 1 predictor to Equation B6:

(B7) Level 1:

$$
\begin{aligned}
\text { CHGBEH }_{\mathrm{ij}}= & \beta_{0 \mathrm{j}}+\beta_{1 \mathrm{j}}\left(\text { OUTRISK }_{\mathrm{ij}}\right)+\beta_{2 \mathrm{j}}\left(\text { OUTREW }_{\mathrm{ij}}\right) \\
& +\beta_{3 \mathrm{j}}\left(\text { PRORISK }_{\mathrm{ij}}\right)+\beta_{4 \mathrm{j}}\left(\text { PROREW }_{\mathrm{ij}}\right)+\beta_{5 \mathrm{j}}\left(\mathrm{PO}_{\mathrm{ij}}\right) \\
& +\beta_{6 \mathrm{j}}\left(\text { PRIMAPP }_{\mathrm{ij}}\right)+\beta_{7 \mathrm{j}}\left(\text { SECAPP }_{\mathrm{ij}}\right)
\end{aligned}
$$




$$
\begin{aligned}
& +\beta_{8 \mathrm{j}}\left(\text { OUTRISK }_{\mathrm{ij}} \times \mathrm{PO}_{\mathrm{ij}}\right)+\beta_{9 \mathrm{j}}\left(\text { OUTREW }_{\mathrm{ij}} \times \mathrm{PO}_{\mathrm{ij}}\right) \\
& +\beta_{10 \mathrm{j}}\left(\text { PRORISK }_{\mathrm{ij}} \times \mathrm{PO}_{\mathrm{ij}}\right)+\beta_{11 \mathrm{j}}\left(\text { PROREW }_{\mathrm{ij}} \times \mathrm{PO}_{\mathrm{ij}}\right) \\
& +\beta_{12 \mathrm{j}}\left(\text { EDUC }_{\mathrm{ij}}\right)+\beta_{13 \mathrm{j}}\left(\text { TENURE }_{\mathrm{ij}}\right) \\
& +\beta_{14 \mathrm{j}}\left(\text { TECHSOPH }_{\mathrm{ij}}\right)+\beta_{15 \mathrm{j}}\left(\text { RELCOMIT }_{\mathrm{ij}}\right) \\
& +\beta_{16 \mathrm{j}}\left(\text { OUTFRAME }_{\mathrm{ij}}\right)+\beta_{17 \mathrm{j}}\left(\text { PROFLEX }_{\mathrm{ij}}\right)+\mathrm{r}_{\mathrm{ij}}
\end{aligned}
$$

Level 2:

$$
\begin{aligned}
\beta_{0 j} & =\gamma_{00}+u_{0 j} \\
\beta_{m j} & =\gamma_{m 0}+u_{m j}, \\
m \in N & =\{1,2, \ldots, 17\} .
\end{aligned}
$$

Table 4 reports the results of the tests of mediation using models outlined in Equations B5, B6, and B7. We analyze each two-level hierarchical linear model outlined in Equations B1-B7 using HLM 6.08, where the models specified at Level 1 and Level 2 are estimated simultaneously.

\section{Distributional and Statistical Assumptions}

Consistent with HLM models in general, our estimation makes the following statistical and distributional assumptions (see Hoffman, Griffin, and Gavin 2000):

1. Level 1 residuals are independent and normally distributed with a mean of 0 and a variance of $\sigma^{2}$ for every Level 1 unit within each Level 2 unit.

2. Level 1 predictors are independent of Level 1 residuals.

3. Random errors at Level 2 are multivariate normal and are independent of Level 2 units.

4. The set of Level 2 predictors is independent of every Level 2 residual.

5. Residuals at Level 1 and Level 2 are independent.

\section{REFERENCES}

Ahearne, Michael, Son K. Lam, John E. Mathieu, and Willy Bolander (2010), "Why Are Some Salespeople Better at Adapting to Organizational Change?" Journal of Marketing, 74 (May), 6-79.

Anderson, Erin and Richard L. Oliver (1987), "Perspectives on Behavior-Based Versus Outcome-Based Sales Force Control Systems," Journal of Marketing, 51 (October), 76-88.

Anderson, James C. and David W. Gerbing (1988), "Structural Equation Modeling in Practice: A Review and Recommended Two-Step Approach," Psychological Bulletin, 103 (3), 411-23.

Armstrong, Scott J. and Terry S. Overton (1977), "Estimating Nonresponse Bias in Mail Surveys," Journal of Marketing Research, 14 (August), 396-402.

Bagozzi, Richard, Youjae Yi, and Lynn W. Phillips (1991), "Assessing Construct Validity in Organizational Research," Administrative Science Quarterly, 36 (3), 421-58.

Baron, Reuben M. and David A. Kenny (1986), "The ModeratorMediator Variable Distinction in Social Psychological Research: Conceptual, Strategic, and Statistical Considerations," Journal of Personality and Social Psychology, 51 (6), 1173-82.

Beehr, Terry A. and Thomas M. Franz (1986), "The Current Debate About the Meaning of Job Stress," Journal of Organizational Behavior Management, 8 (2), 5-18.

Bergen, Mark, Shantanu Dutta, and Orville C. Walker Jr. (1992), "Agency Relationships in Marketing: A Review of the Implications and Applications of Agency and Related Theories," Journal of Marketing, 56 (July), 1-24.

Bliese, Paul D. (2000), "Within-Group Agreement, Nonindependence, and Reliability: Implications for Data Aggregation and
Analysis," in Multilevel Theory, Research, and Methods in Organizations: Foundations, Extensions, and New Directions, Katherine J. Klein and Steven W.J. Kozlowski, eds. San Francisco: Jossey-Bass, 349-81.

Bonoma, Thomas V. (1984), "Making Your Marketing Strategies Work," Harvard Business Review, 62 (March/April), 69-76.

— and Victoria L. Crittenden (1988), "Managing Marketing Implementation," Sloan Management Review, 29 (Winter), 7-14.

Boone, Paula Fitzgerald and Pam Scholder Ellen (1992), "The Generation and Consequences of Communication-Evoked Imagery," Journal of Consumer Research, 19 (June), 93-104.

Bryk, Anthony S. and Stephen W. Raudenbush (1992), Hierarchical Linear Models: Applications and Data Analysis Methods. Thousand Oaks, CA: Sage Publications.

Cadwallader, Susan, Cheryl Burke Jarvis, Mary Jo Bitner, and Amy L. Ostrom (2010), "Frontline Employee Motivation to Participate in Service Innovation Implementation," Journal of the Academy of Marketing Science, 38 (2), 219-39.

Challagalla, Goutam N. and Tasadduq A. Shervani (1996), "Dimensions and Types of Supervisory Control: Effects on Salesperson Performance and Satisfaction," Journal of Marketing, 60 (January), 89-105.

Chang, Edward C. (1998), "Dispositional Optimism and Primary and Secondary Appraisal of a Stressor: Controlling for Confounding Influences and Relations to Coping and Psychological and Physical Adjustment," Journal of Personality and Social Psychology, 74 (4), 1109-1120.

Chimhanzi, Jacqueline and Robert E. Morgan (2005), "Explanations from the Marketing/Human Resources Dyad for Marketing Strategy Implementation Effectiveness in Service Firms," Journal of Business Research, 58 (June), 787-96.

Colletti, Jerome A. and Lawrence B. Chonko (1997), "Change Management Initiatives: Moving Sales Organizations from Obsolescence to High Performance," Journal of Personal Selling and Sales Management, 17 (Spring), 1-30.

Cravens, Donald W., Thomas N. Ingram, Raymond W. LaForge, and Clifford E. Young (1993), "Behavior-Based and OutcomeBased Sales Force Control Systems," Journal of Marketing, 57 (October), 47-59.

Dewe, Philip (1991), "Primary Appraisal, Secondary Appraisal, and Coping: Their Role in Stressful Work Encounters," Journal of Occupational Psychology, 64 (4), 331-51.

Dweck, Carol S. and Ellen L. Leggett (1988), "A Social-Cognitive Approach to Motivation and Personality," Psychological Review, 95 (2), 256-73.

Edmondson, Amy C. (1999), "Psychological Safety and Learning Behavior in Work Teams," Administrative Science Quarterly, 44 (June), 350-83.

—_ , Richard Bohmer, and Gary P. Pisano (2001), "Disrupted Routines: Team Learning and New Technology Implementation in Hospitals," Administrative Science Quarterly, 46 (4), 685-711.

Fang, Eric, Kenneth R. Evans, and Timothy D. Landry (2005), 'Control Systems' Effect on Attributional Processes and Sales Outcomes: A Cybernetic Information-Processing Perspective," Journal of the Academy of Marketing Science, 33 (Fall), 553-74.

Folkman, Susan and Richard S. Lazarus (1985), "If It Changes It Must Be a Process: Study of Emotion and Coping During Three Stages of a College Examination," Journal of Personality and Social Psychology, 48 (1), 150-70.

$-\_,-$Christine Dunkel-Schetter, Anita DeLongis, and Rang J. Gruen (1986), "Dynamics of a Stressful Encounter: Cognitive Appraisal, Coping, and Encounter Outcomes," Journal of Personality and Social Psychology, 50 (5), 992-1003.

Fornell, Claes and David F. Larcker (1981), "Structural Equation Models with Unobservable Variables and Measurement Error: Algebra and Statistics," Journal of Marketing Research, 18 (August), 382-88. 
Harris, Eric G., John C. Mowen, and Tom J. Brown (2005), "Reexamining Salesperson Goal Orientations: Personality Influencers, Customer Orientation, and Work Satisfaction," Journal of the Academy of Marketing Science, 33 (1), 19-35.

Hoffman, David A., Mark A. Griffin, and Mark B. Gavin (2000), "The Application of Hierarchical Linear Modeling to Organizational Research," in Multilevel Theory, Research, and Methods in Organizations: Foundations, Extensions, and New Directions, Katherine J. Klein and Steven W.J. Kozlowski, eds. San Francisco: Jossey-Bass, 467-511.

Hunter, Larry W. and Sherry M. B. Thatcher (2007), "Feeling the Heat: Effects of Stress, Commitment, and Job Experience on Job Performance," Academy of Management Journal, 50 (August), 953-68,

Hurley, Robert F. (1998), "Managing Change: An Ethnographic Approach to Developing Research Propositions and Understanding Change in Sales Organizations," Journal of Personal Selling and Sales Management, 18 (3), 57-71.

Hutt, Michael D. and Thomas W. Speh (1984), “The Marketing Strategy Center: Diagnosing the Industrial Marketer's Interdisciplinary Role," Journal of Marketing, 48 (Fall), 53-61.

Huy, Quy Nguyen (1999), "Emotional Capability, Emotional Intelligence, and Radical Change," Academy of Management Review, 24 (2), 325-45.

Janssen, Onne and Nico van Yperen (2004), “Employees' Goal Orientations, the Quality of Leader-Member Exchange, and the Outcomes of Job Performance and Job Satisfaction," Academy of Management Journal, 47 (June), 368-84.

Jaworski, Bernard J. (1988), "Toward a Theory of Marketing Control: Environmental Context, Control Types, and Consequences," Journal of Marketing, 52 (July), 23-39.

— and Ajay K. Kohli (1991), "Supervisory Feedback: Alternative Types and Their Impact on Salespeople's Performance and Satisfaction," Journal of Marketing Research, 28 (February), 190-201.

Kahn, Robert L. and Philippe Byosiere (1998), "Stress in Organizations," in Handbook of Industrial and Organizational Psychology, Vol. 3, Dunnette, Marvin D. and Hough, Leaetta M., eds. New Delhi, India: Jaico Publishing, 571-650.

Kahneman, Daniel and Amos Tversky (1979), "Prospect Theory: An Analysis of Decision Under Risk," Econometrica, 47 (March), 263-92.

Klein, Katherine J., Paul Bliese, Steve Kozlowski, Fred Dansereau, Mark Gavin, Mark Griffin, et al. (2000), "Multilevel Analytical Techniques: Commonalities, Differences and Continuing Questions," in Multilevel Theory, Research, and Methods in Organizations: Foundations, Extensions, and New Directions, Katherine J. Klein and Steve W.J. Kozlowski, eds. San Francisco: Jossey-Bass, 512-53.

— and Steve W.J. Kozlowski (2000a), "From Micro to Meso: Critical Steps in Conceptualizing and Conducting Multilevel Research," Organizational Research Methods, 3 (3), 211-36.

- and - (2000b), Multilevel Theory, Research, and Methods in Organizations: Foundations, Extensions, and New Directions. San Francisco: Jossey-Bass.

— and JoAnn Speer Sorra (1996), "The Challenge of Innovation Implementation," Academy of Management Review, 21 (4), 1055-80.

Kohli, Ajay K. and Bernard J. Jaworski (1990), "Market Orientation: The Construct, Research Propositions, and Managerial Implications," Journal of Marketing, 54 (April), 1-18.

_ - Tasadduq A. Shervani, and Goutam N. Challagalla (1998), "Learning and Performance Orientation of Salespeople: The Role of Supervisors," Journal of Marketing Research, 35 (May), 263-74.

Lafferty, Alannah E. and Mark A. Griffin (2006), "Perceptions of Organizational Change: A Stress and Coping Perspective," Journal of Applied Psychology, 91 (5), 1154-62.
Latack, Janina C., Angelo Kinicki, and Gregory E. Prussia (1995), "An Integrative Process Model of Coping with Job Loss," Academy of Management Review, 20 (2), 311-42.

Lazarus, Richard S. (1980), "The Stress and Coping Paradigm," in Models for Clinical Psychopathology, C. Eisdorfer, D. Cohen, A. Kleinman, and P. Maxim, eds. New York: Spectrum, 177-214.

_ and Susan Folkman (1984), Stress, Appraisal and Coping. New York: Springer.

Lindell, Michael K. and David J. Whitney (2001), "Accounting for Common Method Variance in Cross-Sectional Research Designs," Journal of Applied Psychology, 86 (February), 114-21.

Lowe, Rob, Kav Vedhara, Paul Bennett, Emily Brookes, Lone Gale, Kathy Munnoch, et al. (2003), "Emotion-Related Primary and Secondary Appraisals, Adjustment, and Coping: Associations in Women Awaiting Breast Disease Diagnosis," British Journal of Health Psychology, 8, 377-91.

Maas, Cora J.M. and Joop J. Hox (2005), "Sufficient Sample Sizes for Multilevel Modeling," Methodology, 1 (3), 86-92.

Mack, David A., Debra L. Nelson, and James Campbell Quick (1998), "The Stress of Organisational Change: A Dynamic Process Model," Applied Psychology, 47 (April), 219-32.

Marshall, J. and C. Cooper (1979), "Work Experience of Middle and Senior Managers: The Pressure and Satisfaction," International Management Review, 19 (1), 81-96.

Morrison, Elizabeth W. and Corey C. Phelps (1999), "Taking Charge at Work: Extrarole Efforts to Initiate Workplace Change," Academy of Management Journal, 42 (August), 403-419.

Noble, Charles H. and Michael P. Mokwa (1999), "Implementing Marketing Strategies: Developing and Testing a Managerial Theory," Journal of Marketing, 63 (October), 57-73.

Onyemah, Vincent and Erin Anderson (2009), "Inconsistencies Among the Constitutive Elements of a Sales Force Control System: Test of a Configuration Theory-Based Performance Prediction," Journal of Personal Selling \& Sales Management, 29 (Winter), 9-24.

Peter, Richard and Johannes Siegrist (1997), "Chronic Work Stress, Sickness Absence and Hypertension in Middle Managers: General or Specific Sociological Explanations?" Social Science \& Medicine, 45 (October), 1111-20.

Raudenbush, Stephen W. and Anthony S. Bryk (2002), Hierarchical Linear Models: Applications and Data Analysis Methods, 2d ed. Thousand Oaks, CA: Sage Publications.

Sarin, Shikhar and Vijay Mahajan (2001), "The Effect of Reward Structures on the Performance of Cross-Functional Product Development Teams," Journal of Marketing, 65 (April), 35-53.

Scott, Susanne G. and Reginald A. Bruce (1994), "Determinants of Innovative Behavior: A Path Model of Individual Innovation in the Workplace," Academy of Management Journal, 37 (June), 580-607.

Self, Dennis R., Achilles A. Armenakis, and Mike Schraeder (2007), "Organizational Change Content, Process, and Context: A Simultaneous Analysis of Employee Reactions," Journal of Change Management, 7 (June), 211-29.

Siegrist, Johannes (1995), "Emotions and Health in Occupational Life: New Scientific Findings and Policy Implications," Patient Education \& Counseling Special Issue: Current Perspectives on GPs and Clinical Health Promotion, 25 (July), 227-36.

Singh, Jagdip and Gary Rhoads (1991), "Boundary Role Ambiguity in Marketing-Oriented Positions: A Multidimensional, Multifaceted Operationalization," Journal of Marketing Research, 28 (August), 328-38.

Sujan, Harish, Barton A. Weitz, and Nirmalya Kumar (1994), "Learning Orientation, Working Smart, and Effective Selling," Journal of Marketing, 58 (July), 39-52.

Teas, R. Kenneth (1981), "An Empirical Test of Models of Salespersons' Job Expectancy and Instrumentality Perceptions," Journal of Marketing Research, 18 (May), 209-226. 
Van Vegchel, Natasja, Jan de Jonge, Arnold B. Bakker, and Wilmar B. Schaufeli (2002), "Testing Global and Specific Indicators of Rewards in the Effort-Reward Imbalance Model: Does It Make Any Difference?" European Journal of Work \& Organizational Psychology, 11 (December), 403-422.

Walker, Orville C., Jr., and Robert W. Ruekert (1987), "Marketing's Role in the Implementation of Business Strategies: A Critical Review and Conceptual Framework," Journal of Marketing, 51 (July), 15-33.
Ye, Jun, Detelina Marinova, and Jagdip Singh (2007), "Strategic Change Implementation and Performance Loss in the Frontlines," Journal of Marketing, 71 (October), 1-18.

Yeo, Gillian, Shayne Loft, Tania Xiao, and Christian Kiewitz (2009), "Goal Orientations and Performance: Differential Relationships Across Levels of Analysis and as a Function of Task Demands," Journal of Applied Psychology, 94 (May), 710-26. 